\title{
Effect of an Alumina Supported Palladium Catalyst on the Magnesium Sulfate Decomposition Kinetics
}

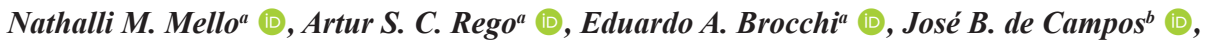 \\ Francisco J. Moura ${ }^{a}$ (), Rodrigo F. M. Souza ${ }^{a *}$ (1) \\ ${ }^{a}$ Pontifícia Universidade Católica do Rio de Janeiro (PUC-Rio), Departamento de Engenharia Química \\ e de Materiais (DEQM), Rio de Janeiro, RJ, Brasil \\ ${ }^{b}$ Universidade do Estado do Rio de Janeiro (UERJ), Departamento de Engenharia Mecânica (DEM), \\ Rio de Janeiro, RJ, Brasil
}

Received: July 29, 2020; Revised: October 05, 2020; Accepted: November 10, 2020

\begin{abstract}
The sulfur related thermochemical water-splitting cycles are an important class of chemical processes considered for hydrogen production. Recently, the magnesium sulfate thermal decomposition has been reported as a potential unit operation in one of these cycles. Therefore, some interest has been observed in the use of catalysts to lower the activation energy of such reactions. In this context, the present manuscript reports the thermodynamics and kinetics modeling results associated with this reaction system in the presence of a Pd catalyst supported over $\gamma-\mathrm{Al}_{2} \mathrm{O}_{3}$. The presence of such species is responsible for shifting the decomposition temperature to lower values in at least $100{ }^{\circ} \mathrm{C}$. It was observed that the magnesium content is still oriented towards $\mathrm{MgO}$ formation. The obtained results indicate that the $\mathrm{Pd} / \mathrm{Al}_{2} \mathrm{O}_{3}$ catalyst could be a good alternative in reducing the thermal decomposition temperature as its presence was responsible for diminishing the process activation energy from 368.2 to $258.8 \mathrm{~kJ} \cdot \mathrm{mol}^{-1}$.
\end{abstract}

Keywords: Thermal decomposition, kinetics, $\mathrm{MgO} / \mathrm{MgSO}$, sulfur water-splitting cycles, $\mathrm{Pd}$ catalyst.

\section{Introduction}

Over the last decades, the debate regarding how the energy systems must be updated to reduced carbon emissions and lower its contribution to climate change has increased remarkably. This could be observed in international agencies' reports, such as the United Nations ${ }^{1}$, as well as through studies of affordability and security of this future approaches ${ }^{2}$. In this context, hydrogen presents itself as a potential alternative to replace carbon-based fossil fuels and, for this reason, the research on the production and storage routes of this resource is considered strategical for sustainable development ${ }^{3,4}$. Besides the competitive aspect of this alternative in comparison to the other, one of the features of the hydrogen-based system is the production of water as a byproduct which is a friendly outcome of the process.

The studied methods for obtaining $\mathrm{H}_{2}$ are diverse, however, not all of them are from renewable sources, and the most relevant alternatives, so far, are based on methane decomposition ${ }^{5-7}$ and thermochemical water-splitting cycles. The latter has also many proposed sub-systems with the sulfurbased route being one of the most studied alternatives ${ }^{8-11}$. Recently, it has been reported an increased interest in the metal sulfates decomposition as a potential reaction system for sulfur oxides production for such water-splitting cycles $^{12-15}$.

Metal sulfates are normally formed either from sulfuric acid digestion of oxides or through the oxidation of sulfides,

*e-mail: rsouza@puc-rio.br being widely used in technological applications ${ }^{16,17}$. Their characteristic sulfur oxyanions have the formula $\mathrm{SO}_{4}{ }^{-2}{ }^{18}$, which helps the sulfates be highly soluble in water, with a few exceptions, such as $\mathrm{CaSO}_{4}{ }^{19}$. Regarding the thermal stability behavior, sulfates mostly decompose into metal oxides with the evolution of sulfur oxides $\left(\mathrm{SO}_{2}\right.$ and $\left.\mathrm{SO}_{3}\right)$ and oxygen $\left(\mathrm{O}_{2}\right)$. These characteristics motivate chemical industrial process developments in which this type of material is used as a source of sulfur oxides, such as sulfuric acid manufacturing ${ }^{20}$ and sulfur-iodine cycles for hydrogen production ${ }^{12-14}$.

In parallel, over the last years, there has been an increasing interest in the chemical industries to adapt their flowcharts to optimize energy consumption. Therefore, an intensifying effort to lower the processes operational temperatures as well as the wasted energy recovering in some unitary operations has been observed ${ }^{21}$. The most relevant alternatives are associated with the development of a reductive atmosphere ${ }^{22}$ as well as the use of catalysts ${ }^{15}$ to enhance the thermal decomposition mechanism towards sulfur oxide formation. For the latter, the contribution to lowering the decomposition temperature in water-splitting cycles could provide an energetic advantage in solar-based operations.

Bhosale ${ }^{23}$ recently presented the thermodynamics considerations for a solar-based thermochemical water-splitting cycle based on the decomposition of $\mathrm{MgSO}_{4}$. In his work, depending on the molar flow of argon the decomposition 
temperature shifts from 1217 to $1009{ }^{\circ} \mathrm{C}$. The proposed method is based on Equations 1 and 2, respectively detailing the thermal decomposition and hydrogen production. Equation 3 represents the global reaction which characterizes this system as a thermochemical water-splitting cycle.

$$
\begin{aligned}
& \mathrm{MgSO}_{4} \rightarrow \mathrm{MgO}+\mathrm{SO}_{2}(g)+\frac{1}{2} \mathrm{O}_{2}(g) \\
& \mathrm{MgO}+\mathrm{SO}_{2}(g)+\mathrm{H}_{2} \mathrm{O}(g) \rightarrow \mathrm{MgSO}_{4}+\mathrm{H}_{2}(g) \\
& \mathrm{H}_{2} \mathrm{O}(\mathrm{g}) \rightarrow \mathrm{H}_{2}(g)+\frac{1}{2} \mathrm{O}_{2}(g)
\end{aligned}
$$

$\mathrm{MgSO}_{4}$ is a compound which may contain from one to twelve hydrations molecules in it, as have already been reported in the literature. The anhydrous salt is not easily formed while $\mathrm{MgSO}_{4} \cdot \mathrm{H}_{2} \mathrm{O}$ (Kieserite) and $\mathrm{MgSO}_{4} \cdot 7 \mathrm{H}_{2} \mathrm{O}$ (Epsom salt) are the most common forms found in the nature ${ }^{24-26}$.

Present in the leaching liquors of some hydrometallurgical processes, in which Mg-rich ores, such as nickel-cobalt laterites, are treated, magnesium sulfate could be a major component of the waste stream. In industrial processes, the leach residue is generally not pure since it contains smaller amounts of other sulfates, such as iron, aluminum, and manganese. The decomposition of the eventually precipitated sulfates can be a route to obtain sulfur dioxide and metal oxides ${ }^{27,28}$.

Over the years, under a different perspective, the thermal decomposition of magnesium sulfate has already been applied to aim the production of sulfur dioxide, for sulfuric acid manufacturing, and magnesium oxide, as a neutralizing agent, for $\mathrm{pH}$ control during other sulfates precipitation as well as for heat storage unit operations ${ }^{29-32}$. Moreover, the decomposition of this salt has been continuously studied throughout the last decades, under different reaction conditions, such as atmosphere composition and presence of a reducing agent $^{26,31,33-37}$; to optimize the process in terms of the oxide particle size by lowering the decomposition temperature.

Another alternative to successfully do that is the use of catalysts that can act through product selectivity. Knittel et al. ${ }^{38}$ carried-out a study related to magnesium sulfate decomposition in a temperature range between 627 and $727^{\circ} \mathrm{C}$ by using different catalysts. $\mathrm{Pt}, \mathrm{Ir}, \mathrm{Ru}, \mathrm{Cr}_{2} \mathrm{O}_{3}$, $\mathrm{Cu}_{2} \mathrm{O}, \mathrm{Fe}_{2} \mathrm{O}_{3}, \mathrm{CoO}, \mathrm{NiO}, \mathrm{Mn}_{3} \mathrm{O}_{4}$ were used, being Pt and $\mathrm{Cr}_{2} \mathrm{O}_{3}$ the most effective ones.

As kinetic data may have an important role in understanding the chemical process, several authors have performed experimental studies on the thermal decomposition of metal sulfates ${ }^{39-42}$. The thermal decomposition of anhydrous magnesium sulfate was carried out by Brownell ${ }^{43}$ at temperatures between 890 and $972{ }^{\circ} \mathrm{C}$ applying thermogravimetric analysis with an air atmosphere, reporting apparent activation energy of $343.1 \mathrm{~kJ} \mathrm{~mol}^{-1}$. Hulbert ${ }^{33}$ performed similar experiments, using a different temperature range, from 920 to $1080{ }^{\circ} \mathrm{C}$, obtaining activation energy of $311.7 \mathrm{~kJ} \mathrm{~mol}^{-1}$ while L'vov and Ugolkov ${ }^{44}$ studied the same no catalyst thermal decomposition under vacuum at $730{ }^{\circ} \mathrm{C}$, founding activation energy of $335.7 \mathrm{~kJ} . \mathrm{mol}^{-1}$.

However, there is an apparent paucity of information concerning the kinetics effects of adding catalysts on the metal sulfates thermal decomposition behavior, consequently, on the quantitative approach of the reaction progress. This applies to the $\mathrm{MgSO}_{4}$ reaction system.
Therefore, this study is aimed to contribute to a better chemical understanding of metal sulfates decomposition in the presence of a catalyst and, as for the first approach, magnesium sulfate $\left(\mathrm{MgSO}_{4}\right)$ was selected, as this salt tends to decompose directly to magnesium oxide $(\mathrm{MgO})$ without an intermediate product formation. Hence, the present work aims to give a contribution to the subject by studying the mentioned decomposition reaction with and without the presence of a $\mathrm{Pd} / \mathrm{Al}_{2} \mathrm{O}_{3}$ catalyst using a thermogravimetric system in an inert atmosphere. Thermodynamic and kinetic approaches were implemented to determine the thermochemical tendency as well as the reaction activation energies, respectively. The study is complemented by the characterization of the involved materials using X-Ray Diffraction (XRD) and Field Emission Gun Scanning Electron Microscopy (FEG-SEM).

\section{Methodology}

\subsection{Equilibrium analysis}

Thermodynamics calculations of the magnesium sulfate decomposition were performed through the Gibbs energy minimization method (by calculating the equilibrium composition as a function of temperature), available in the Equilibrium Module of the software HSC Chemistry 9.9 $9^{45}$.

\subsection{Catalyst synthesis}

In the preparation of the $\mathrm{Pd} / \mathrm{Al}_{2} \mathrm{O}_{3}$ catalyst, the singlephase alumina support comes from the aluminum hydroxide (Plural SB - SASOL) calcination at $500{ }^{\circ} \mathrm{C}$ for $8 \mathrm{~h}$ with a heating rate of $10{ }^{\circ} \mathrm{C} \cdot \mathrm{min}^{-1}$. It was then submitted to the impregnation method with palladium. The concentration of the impregnation solution was calculated based on the mass and porosity of the support. The details of the preparation and characterization of this type of catalyst can be found in the works done by Mello ${ }^{46}$ and Montani ${ }^{47}$. In short, the catalyst containing $0.3 \mathrm{wt} \% \mathrm{Pd}$ over an alumina support was prepared using a manufactured solution of $\mathrm{Pd}\left(\mathrm{NH}_{3}\right)_{4} \mathrm{Cl}_{2} \cdot \mathrm{H}_{2} \mathrm{O}$. The impregnation was done by the dropwise addition of the solution containing the metal, followed by intense mixing to obtain an adequate distribution of the Pd precursor. The obtained palladium supported on alumina was dried at $110^{\circ} \mathrm{C}$ for $18 \mathrm{~h}$ and then calcined at $500{ }^{\circ} \mathrm{C}$ in a muffle furnace through $1 \mathrm{~h}$ with a heating rate of $10^{\circ} \mathrm{C} \cdot \mathrm{min}^{-1}$.

\subsection{Thermogravimetric analysis (TGA)}

The non-isothermic campaigns were performed using magnesium sulfate heptahydrate (Merck - analytical grade) with and without 20 wt. $\% \mathrm{Pd} / \mathrm{Al}_{2} \mathrm{O}_{3}$ in a Netzsch thermogravimetric analyzer model STA 449 F3 Jupiter. The analysis was carried out in an inert atmosphere of ultra-pure $\mathrm{N}_{2}$ (Linde AG) with a volumetric flow of $20 \mathrm{~mL} \cdot \mathrm{min}^{-1}$ and a heating rate of $10^{\circ} \mathrm{C} \cdot \mathrm{min}^{-1}$ from room temperature until $1400^{\circ} \mathrm{C}$. The proportion of $\mathrm{MgSO}_{4} \cdot 7 \mathrm{H}_{2} \mathrm{O}$ and $\mathrm{Pd} / \mathrm{Al}_{2} \mathrm{O}_{3}$ was established and softly combined using mortar and pestle, to provide optimal contact between the solids, avoiding any non-chemical effect on the whole reaction system. The use of a small amount of the catalyst is planned for future works but this study was primarily conducted aiming at an easier characterization of the obtained products, which can contribute to better the understanding of the whole reaction mechanism. 


\section{$2.4 X$-ray diffraction $(X R D)$}

Phase formation characterization was performed using XRD (X-Ray Diffraction) techniques. XRD measurements were carried out on these samples using a Panalytical X'PERT PRO and D-8 Bruker Discovery diffractometer with $\mathrm{CuK} \alpha$ and $\mathrm{CoK} \alpha$ radiation respectively, a scanning step of $0.05^{\circ}$ and a collecting time of 5 seconds per step. Quantitative Rietveld calculations ${ }^{48}$ was done using TOPAS Academic ${ }^{49}$, which includes First Principals (FP) calculations for phase determination. For these calculations, the lattice parameter, the crystalline size, and the scale were adjusted where the value of the former parameter indicated the weight phase percentage.

\subsection{Field emission gun scanning electron microscopy (FEG-SEM)}

SEM images were obtained using FEG-SEM Jeol 7100FT. The images scanning was performed using Secondary (SE) and Backscattered (BSE) electron detectors with $15 \mathrm{kV}$ electron acceleration. The BED-C mode detection, which uses BSE, has enhanced the atomic number (Z) image contrast of the constituent phases.

\subsection{Kinetic modeling}

The graphical method proposed by Vachuška and Vobořil ${ }^{50}$, and well described by Speyer ${ }^{51}$ was used to model the TGA experimental data. The first step was to convert the mass loss into weight fraction using Equation 4.

$f=\frac{m-m_{0}}{m_{f}-m_{0}}$

where $f$ is the weight fraction, $m$ is the mass loss value at a given time value, $m_{0}$ is the initial mass loss value, and $m_{f}$ is the final mass loss value.

The variation of the weight fraction in respect to time can be described as the Equation 5

$\frac{d f}{d t}=k_{0} \exp \left(-\frac{E_{a}}{R T}\right) m_{0}^{n-1}(1-f)^{n}$

where $t$ is the time, $k_{0}$ is the pre-exponential factor, $R$ is the universal gas constant, $T$ is the temperature, $n$ is the apparent reaction order, and $E_{a}$ is the activation energy.

Applying the natural logarithm on both sides and differentiating the resulting equation yields in the Equation 6 .

$\frac{d}{d t}\left(\ln \left(\frac{d f}{d t}\right)\right)=\frac{d^{2} f / d t^{2}}{d f / d t}=-\frac{n(d f / d t)}{1-f}+\frac{E_{a}}{R T^{2}} \frac{d T}{d t}$

Considering that $\frac{d T}{d t}$ is the heating rate $(\phi)$ and that the temperature is a function of time, $T=\left(\phi t+T_{r}\right)$.

Once this step is done, all the values can be used in Equation 7.

$\left(\phi t+T_{r}\right)^{2} \frac{d^{2} f / d t^{2}}{d f / d t}=-n\left[\frac{\left(\phi t+T_{r}\right)^{2}(d f / d t)}{1-f}\right]+\frac{E_{a} \phi}{R}$

where $T_{r}$ is the reference temperature obtained from theGA data.

The plot of all the values yields the apparent reaction order and activation energy from the angular and linear coefficients, respectively.

One issue regarding this method is the error encountered when calculating the derivatives. Normally, these are obtained using the finite difference method, which already carries on error due to the approximations made. Furthermore, the TGA data has noise, which increases the error values for derivatives calculations.

To work around this problem, it was proposed to approximate the weight fraction data to a known analytical function, which eliminates the error in the derivatives. Due to the similarity, the sigmoidal function was used to approximate the weight fraction values. This function is displayed in Equation 8.

$$
f(x)=\frac{1}{1+e^{-(a x+b)}}
$$

The ' $a$ ' and ' $b$ ' parameters represent the smoothness and inflection point, respectively. Their values were obtained by using the native MATLAB function 'fminsearch', which is a modified simplex method. With the sigmoidal function defined, the values of weight fraction and the derivatives can be used in Equation 7 to calculate the apparent reaction order and activation energy values. All the calculations were made using MATLAB $2019 \mathrm{~b}^{52}$.

\section{Results and Discussion}

\subsection{Equilibrium analysis}

Figure la presents the molar percentage of the equilibrium composition as a function of temperature for the $\mathrm{MgSO}_{4}$
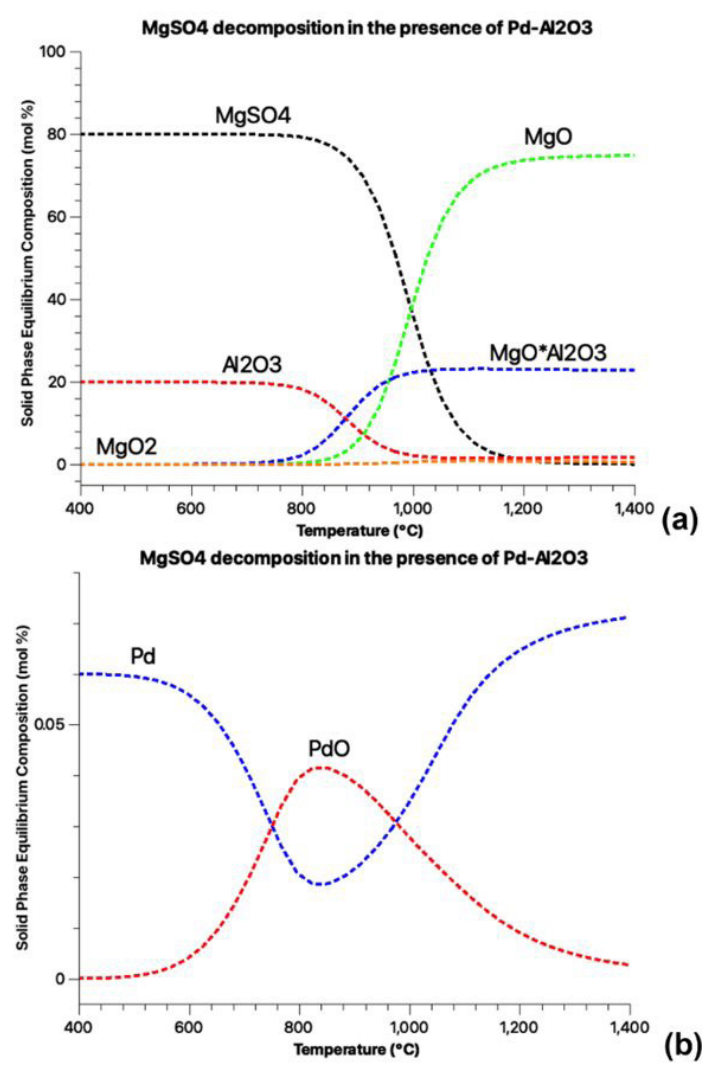

Figure 1. Solid-phase equilibrium composition as a function of temperature: (a) magnesium and aluminum bearing species; (b) palladium bearing species. 
decomposition in the presence of $\mathrm{Pd}$ and $\mathrm{Al}_{2} \mathrm{O}_{3}$. It can be observed that $\mathrm{MgO}$ and $\mathrm{MgO} \cdot \mathrm{Al}_{2} \mathrm{O}_{3}$ are the major solid products of the reaction system, with the former accountable for most of the magnesium content. It can be noticed that after $640{ }^{\circ} \mathrm{C}$ the $\mathrm{MgSO}_{4}$ starts to decompose forming preferentially a solid solution with the oxides of magnesium and aluminum. After $1000{ }^{\circ} \mathrm{C}, \mathrm{MgO}$ becomes the major magnesium bearing species. Around $1240{ }^{\circ} \mathrm{C}$, it can be verified that $\mathrm{MgSO}_{4}$ is fully decomposed. It is important to clarify that these thermodynamics calculations consider a closed type of system. Therefore, in an open reaction system with frequent gaseous product removal, the equilibrium conditions could be shifted to lower temperatures. Figure 1b, on another scale but for the same conditions, shows the equilibrium conditions behavior, considering very low amounts of Pd, such as those of an impregnated catalyst over ceramic support. It was observed that palladium tends to oxidize and then dissociate back to the metallic form within the reaction system which can be an indication of possible interaction with some of the gaseous products of the reaction system, such as $\mathrm{SO}_{3}, \mathrm{SO}_{2}$ and $\mathrm{O}_{2}$.

Figure 2 shows the molar composition of the gas phase produced, at equilibrium condition, as a function of the temperature. It can be seen that $\mathrm{SO}_{2}$ tends to be the major sulfur-containing species. The $\mathrm{SO}_{3}$ produced are minimal, while the $\mathrm{O}_{2}$ amounts are proportional to the stoichiometry of the decomposition reaction depicted in Equation 1.

Figure 3 presents a comparison, based on the equilibrium condition, of the $\mathrm{MgSO}_{4}$ decomposition, with and without $\mathrm{Pd}$ and $\mathrm{Al}_{2} \mathrm{O}_{3}$, in the reaction system from $400{ }^{\circ} \mathrm{C}$ to $1400^{\circ} \mathrm{C}$. The molar amount at equilibrium, as well as the first derivative of both curves, indicate that this metal sulfate seems to be less stable, thermodynamically speaking, in the presence of palladium and alumina. The decomposition reaction tends to start at lower temperatures, probably due to the $\mathrm{MgO} \cdot \mathrm{Al}_{2} \mathrm{O}_{3}$ formation. It is also observed that full conversion can be achieved at the same temperature $\left(1240^{\circ} \mathrm{C}\right)$.

\subsection{Thermogravimetric Analysis}

Thermogravimetric analyzes were carried out with only $\mathrm{Pd} / \mathrm{Al}_{2} \mathrm{O}_{3}$ catalyst as well as with the anhydrous magnesium sulfate with and without the presence of the catalyst. Souza et al. ${ }^{37}$ showed that the mass loss of the seven water molecules of the magnesium sulfate heptahydrate occurs between $100{ }^{\circ} \mathrm{C}$ and $350{ }^{\circ} \mathrm{C}$. Therefore, the TGA results are presented above $400{ }^{\circ} \mathrm{C}$ for a better level of detail.

Motivated by results of the thermodynamics calculations, it was previously carried out a non-isothermic campaign for the $\mathrm{MgSO}_{4}$ decomposition with only $\mathrm{Al}_{2} \mathrm{O}_{3}$, without the presence of Pd over the ceramic support. No difference in thermal behavior was observed, suggesting that no kinetics advantage is obtained without the presence of palladium.

In Figure $4 \mathrm{a}$ is showed the mass loss of the $\mathrm{Pd} / \mathrm{Al}_{2} \mathrm{O}_{3}$ catalyst above $400{ }^{\circ} \mathrm{C}$. It can be observed that this value remains constant at about $14 \%$ up to $1400{ }^{\circ} \mathrm{C}$, this mass loss is probably due to adsorbed water and crystal transformation. This result is in accordance with the observations of Li et al. ${ }^{53}$.

Figure $4 \mathrm{~b}$ shows TGA results of the magnesium sulfate thermal decomposition with and without $20 \mathrm{wt} . \% \mathrm{Pd} / 2 \mathrm{O}_{3}$. In the results presented, both the catalyst mass and the mass loss of the catalyst have been suppressed. The thermal decomposition of the magnesium sulfate without the presence of catalyst starts above $950^{\circ} \mathrm{C}$, possibly producing magnesium oxide and gaseous sulfur dioxide and oxygen. The thermal decomposition ends at a temperature around $1150{ }^{\circ} \mathrm{C}$, with $66 \%$ final mass loss, close to those results showed by Scheidema and Taskinen ${ }^{26}$. The presence of the $\mathrm{Pd} / \mathrm{Al}_{2} \mathrm{O}_{3}$ catalyst reduces both the start and end temperatures of the thermal sulfate decomposition to 830 and $1050{ }^{\circ} \mathrm{C}$, respectively.

\section{$3.3 \mathrm{X}$-ray diffraction}

Figure 5 presents the XRD pattern of the synthesized $\mathrm{Pd} / \mathrm{Al}_{2} \mathrm{O}_{3}$ catalyst. Peaks with an extended base can be observed through the full extent of angle positions. This is an interesting indication that the resulting material can be composed of nanostructured particles. A cubic phase was identified for alumina, suggesting that this oxide was obtained in the gamma form. The metallic palladium impregnated in the sample was also observed in this analysis. The Rietveld

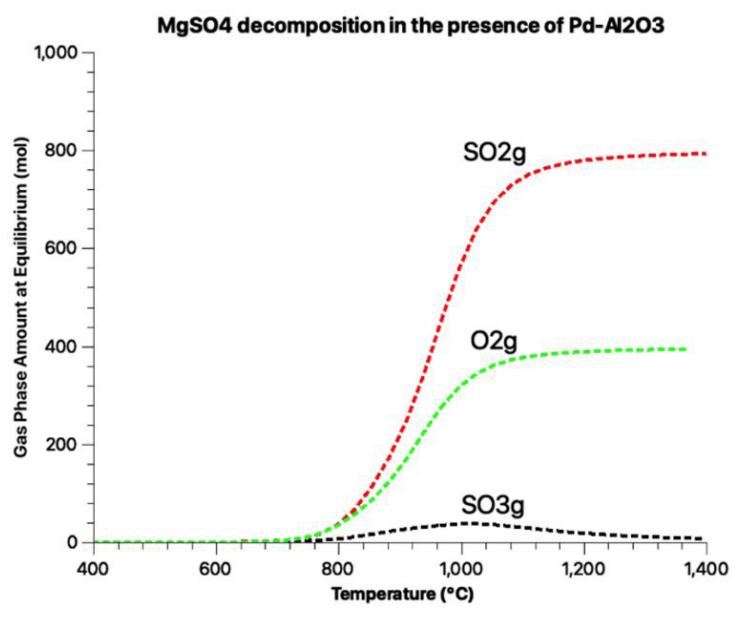

Figure 2. Gas-phase species amount at equilibrium condition as a function of temperature.

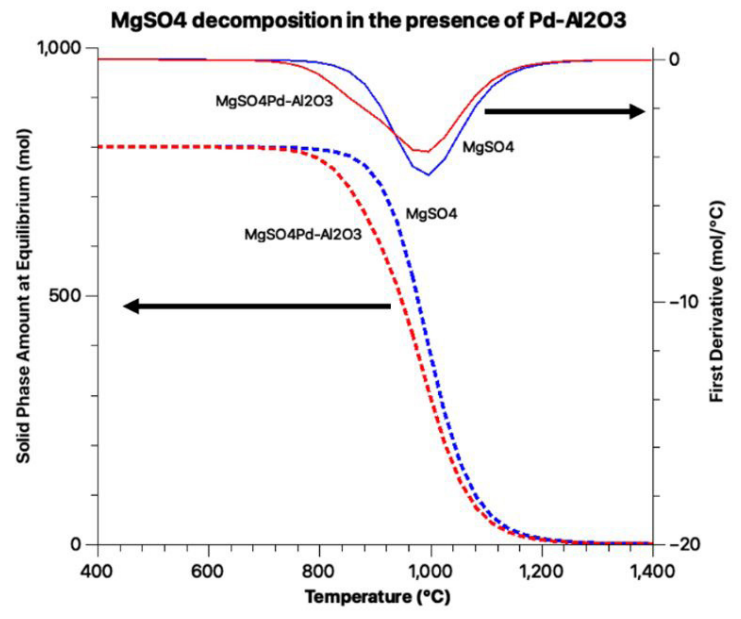

Figure 3. $\mathrm{MgSO}_{4}$ behavior with or without $20 \%$ (wt./wt.) of $\mathrm{Pd} /$ $\mathrm{Al}_{2} \mathrm{O}_{3}$ material depicted by means of solid-phase species amount at equilibrium as a function of temperature. 
semi-quantitative analyses were performed resulting in 95.24 wt. $\%$ of $\mathrm{Al}_{2} \mathrm{O}_{3}$ and 4.76 wt.\% of $\mathrm{Pd}$. The crystallite size evaluated for palladium and alumina was $3.31 \mathrm{~nm}$ and $4.54 \mathrm{~nm}$, respectively. This characteristic is an important feature for the performance of this material as a catalyst in heterogeneous reactions.

Figure 6 shows the XRD results obtained for anhydrous magnesium sulfate decomposition without the presence of the $\mathrm{Pd} / \mathrm{Al}_{2} \mathrm{O}_{3}$ catalyst. As expected, the decomposition product is mainly composed of $\mathrm{MgO}$. Considering a theoretical mass
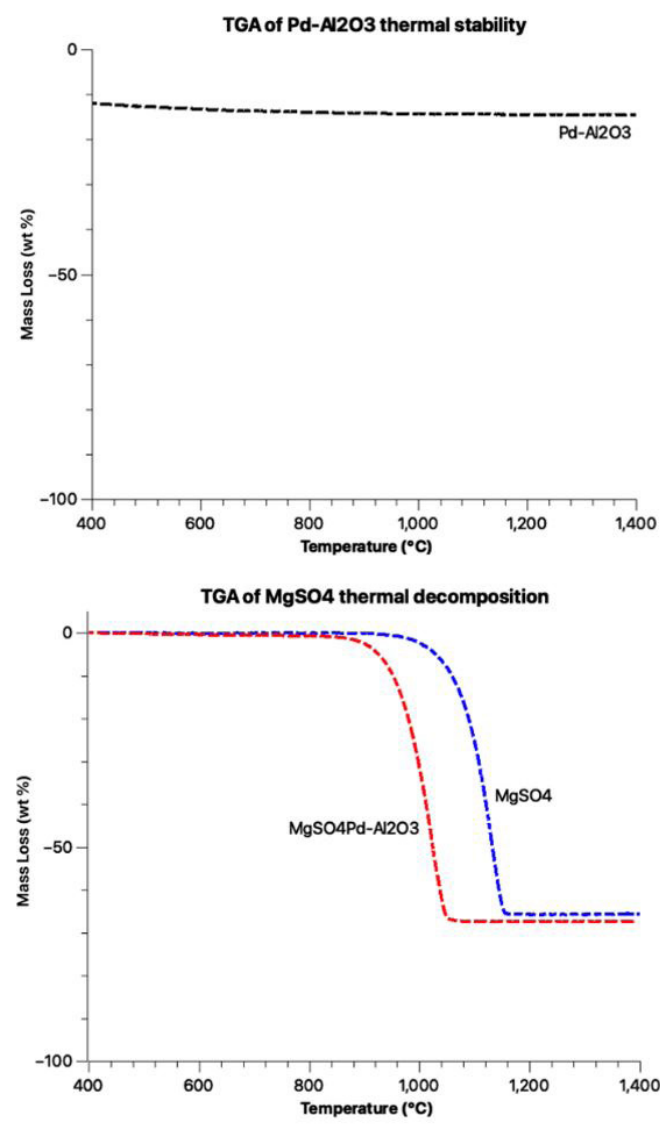

(a)

Figure 4. Thermogravimetric Analysis (TGA): (a) $\mathrm{Pd} / \mathrm{Al}_{2} \mathrm{O}_{3}$ thermal stability; (b) Effect of the presence of $\mathrm{Pd} / \mathrm{Al}_{2} \mathrm{O}_{3}$ over the thermal decomposition behavior. loss of $66.52 \%$ and the observed TGA results a conversion of $98.83 \%$ could be estimated for the process without the catalyst. However, for small angles, some minor peaks were not properly adjusted. A qualitative assessment was made, and it was observed that these peaks agree with a monoclinic form of magnesium sulfate, corroborating the occurrence of a residual starting material in the final product.

Figure 7 shows the XRD results for the $\mathrm{MgSO}_{4}$ thermal decomposition in the presence of the $\mathrm{Pd} / \mathrm{Al}_{2} \mathrm{O}_{3}$ material. It is interesting to observe that, as expected by thermodynamics evaluation, an oxidized phase containing $\mathrm{Mg}$ and $\mathrm{Al}$ was obtained and contributed for $2.62 \mathrm{wt} . \%$ of the final material. Most of the magnesium content is still oriented towards $\mathrm{MgO}$ formation. This phase is responsible for $31.65 \mathrm{wt} \%$ of the decomposition product. The $\mathrm{Al}_{2} \mathrm{O}_{3}$ was quantified as 65.46 wt. $\%$ of the final mass of the sample. Pd was also presented in its metallic form with $0.26 \%$, corroborating the thermodynamics predictions. Considering the $\mathrm{MgSO}_{4} \cdot 7 \mathrm{H}_{2} \mathrm{O}$ conversion into $\mathrm{MgO}$ and the stability of the $\mathrm{Al}_{2} \mathrm{O}_{3}$, these results are very consistent with the expected one. The theoretical mass-balance results are $39.56 \mathrm{wt} \%$ and 60.44 wt.\%, respectively, for $\mathrm{MgO}$ and $\mathrm{Al}_{2} \mathrm{O}_{3}$. However, it is worthwhile to mention that this material may be obtained with a smaller percentage of $\mathrm{Al}_{2} \mathrm{O}_{3}$ since it depends on the initial mass ratio between sulfate and catalyst. Our research group is working on the catalysts fraction variation effect on the behavior and characteristics of this reaction system for future developments.

\subsection{Field emission gun scanning electron microscopy (FEG-SEM)}

For the morphological appreciation of the $\mathrm{Pd} / \mathrm{Al}_{2} \mathrm{O}_{3}$ material it can be seen, in Figure $8 \mathrm{a}$, an image obtained by secondary electrons while Figure $8 \mathrm{~b}$ highlights the composition distinctions, through atomic number enhancement, in the same area of observation. The magnification used in both images was $4300 \times$. It was observed that the particle has an orange-peel type of surface aspect with some small rods distributed in scattered way over the surface. The BED-C detection mode highlights these small rods in bright tones within the grayscale. This is an important qualitative indicative of palladium presence in this sample as the average atomic number of this element $\left(Z_{\mathrm{Pd}}=46\right)$ is much higher than the ones associated with aluminum $\left(Z_{A l}=13\right)$ and oxygen $\left(Z_{O}=8\right)$.

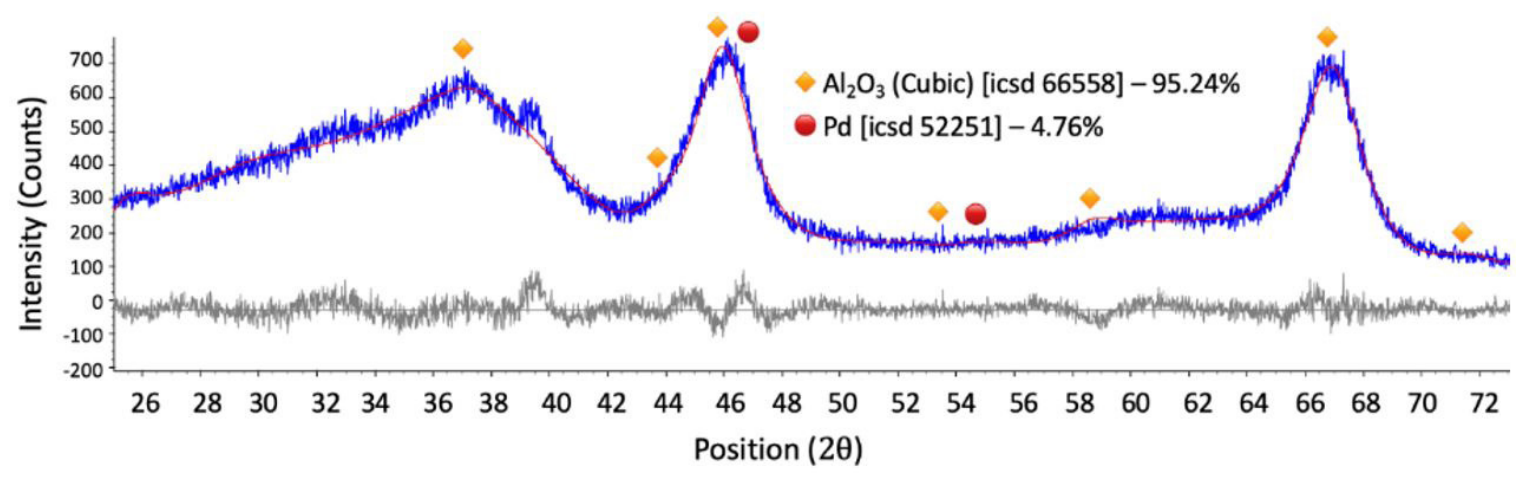

Figure 5. XRD pattern of the $\mathrm{Pd} / \mathrm{Al}_{2} \mathrm{O}_{3}$ material. 


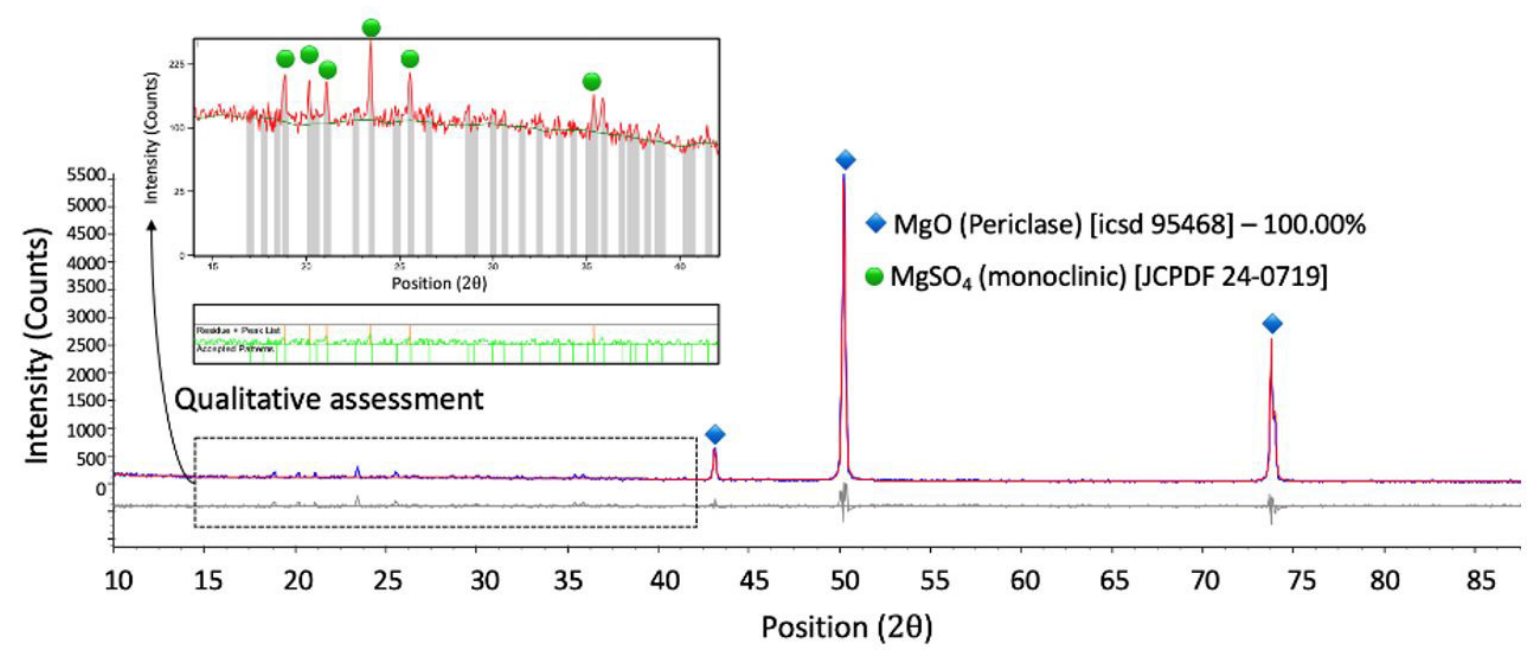

Figure 6. XRD pattern for the decomposition product of $\mathrm{MgSO}_{4}$ without $\mathrm{Pd} / \mathrm{Al}_{2} \mathrm{O}_{3}$ material.

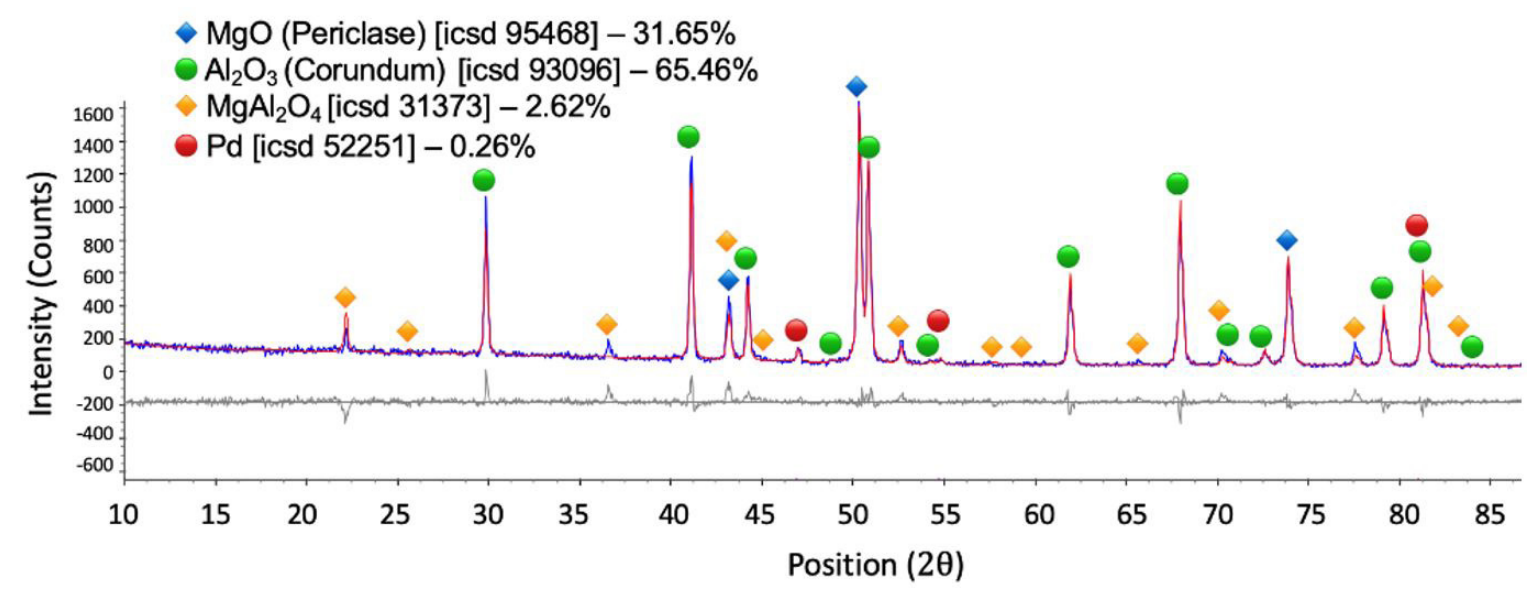

Figure 7. XRD pattern for the decomposition product of $\mathrm{MgSO}_{4}$ with $20 \%$ (wt./wt.) of $\mathrm{Pd} / \mathrm{Al}_{2} \mathrm{O}_{3}$ material.

Previous developments suggest that the $\mathrm{MgSO}_{4}$ thermal decomposition occurs forming $\mathrm{MgO}$ particles similar to a fractured surface. This characteristic was detailed in Brocchi et al. ${ }^{54}$ and Cardoso ${ }^{55}$ for the study of magnesium sulfate heptahydrate thermal decomposition in the presence or not of a hydrogen reductive atmosphere. Figure 9a suggests that, in this work, the $\mathrm{MgO}$ could have been possibly formed in the same manner. It is interesting to mention that this image was captured in the BED-C detection mode and it can be observed that there is no formation brightly presented, suggesting that palladium is probably not incorporated over magnesium bearing particles. The magnification of $550 \times$ also suggests that this particle is not made of the $\mathrm{Pd} / \mathrm{Al}_{2} \mathrm{O}_{3}$ material. Figure $9 \mathrm{~b}$ shows also through the BED-C mode a $7000 \times$ magnification image of a particle with similar features to those described in Figure 8. However, it can be noticed some rugosity over the surface which can be indicative of the formation of the $\mathrm{MgAl}_{2} \mathrm{O}_{4}$ identified in XRD and predicted by the thermodynamics calculations.

\subsection{Kinetic modeling}

Figure 10 shows the experimental weight fraction and the sigmoidal approximation for the thermal decomposition of anhydrous magnesium sulfate with and without the $\mathrm{Pd} /$ $\mathrm{Al}_{2} \mathrm{O}_{3}$ catalyst. The $\mathrm{R}^{2}$ values indicate that the sigmoid function is in good agreement with the TGA experimental results. Furthermore, the plots show how the catalyst affects the reaction, lowering the temperature in which the weight fraction begins to increase.

The kinetic parameters, activation energy, and apparent reaction order are obtained using the Equation 7. Figure 11 depicts the plots for the cases with and without the catalyst.

The $\mathrm{R}^{2}$ values indicate a good linear fitting for both cases. The activation energy and apparent reaction order are obtained by the angular and linear coefficients, respectively. The values of these kinetic parameters are displayed in Table 1.

The activation energy calculated in this work without the catalyst presence is in agreement with those reported by Brownell $^{43}$, Hulbert ${ }^{33}$, and L'vov and Ugolkov ${ }^{44}$. Thus, it is appropriated to estimate that the activation energy reduction 


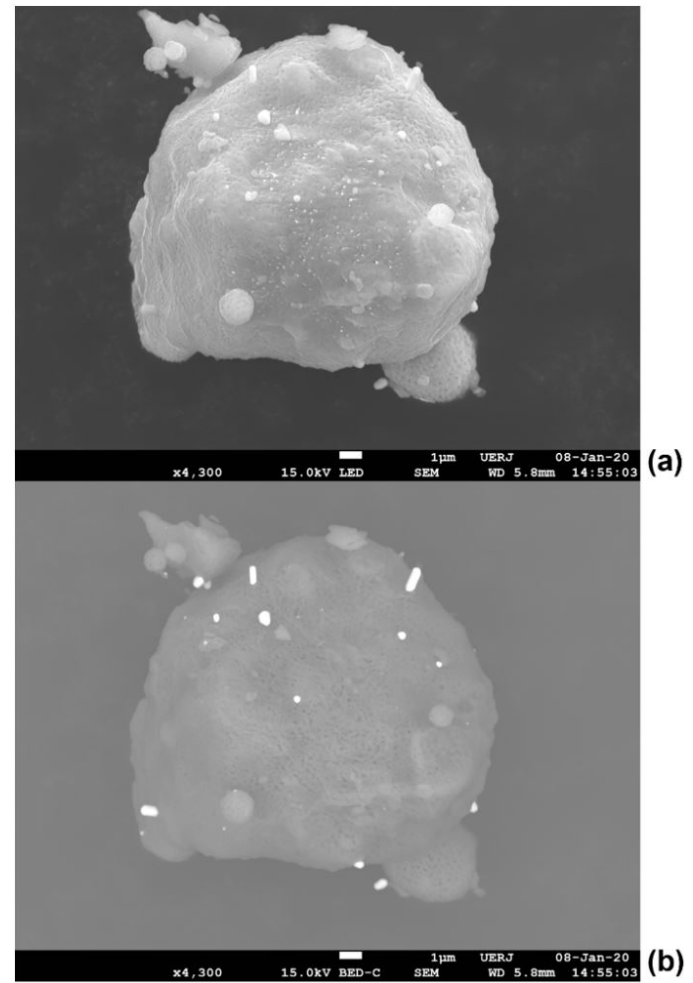

Figure 8. FEG/SEM images of the synthesized $\mathrm{Pd} / \mathrm{Al}_{2} \mathrm{O}_{3}$ material: (a) secondary electrons; (b) backscattered electrons.

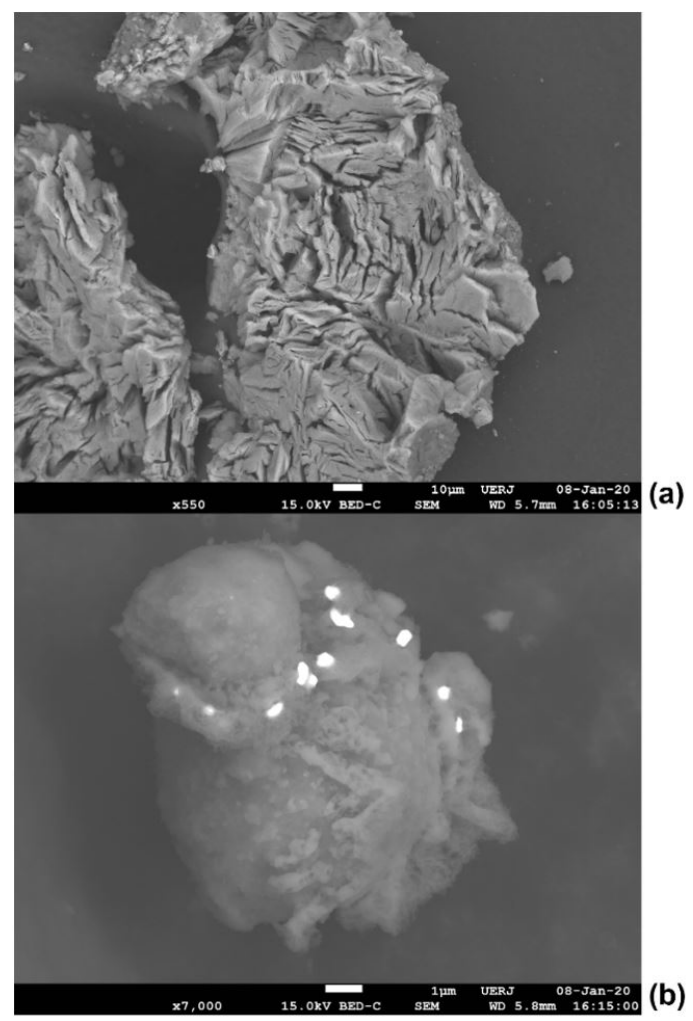

Figure 9. FEG/SEM images of the decomposition product of $\mathrm{MgSO}_{4}$ with $20 \%$ (wt./wt.) of $\mathrm{Pd} / \mathrm{Al}_{2} \mathrm{O}_{3}$ material: (a) secondary electrons image showing the cracked surface of a possible $\mathrm{MgO}$ particle; (b) backscattered electrons image of a palladium bearing particle.
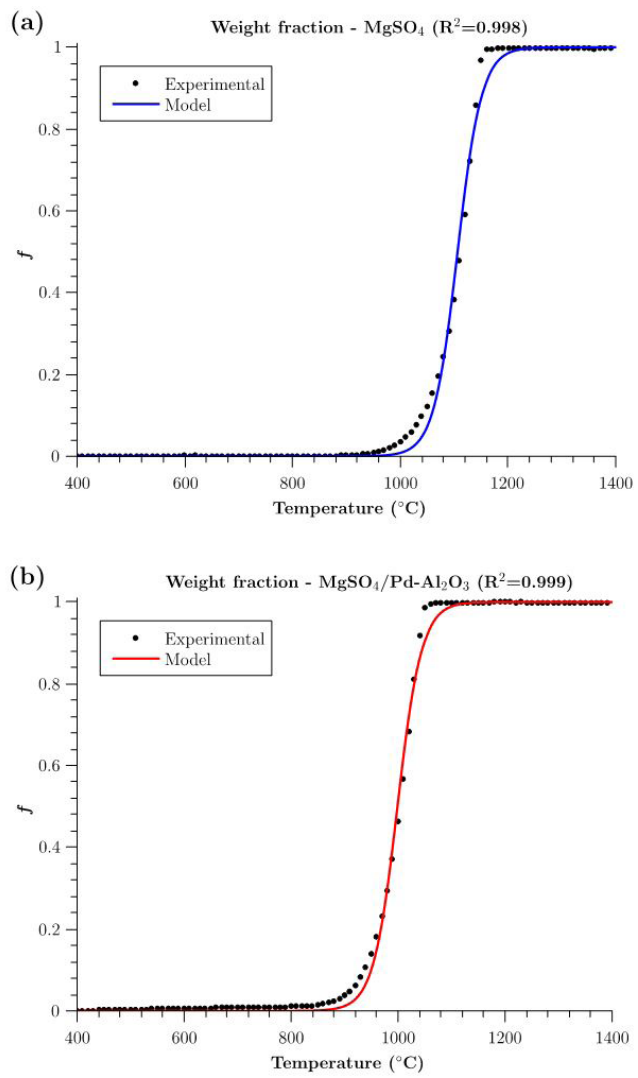

Figure 10. Experimental and sigmoidal approximation values of the weight fraction: (a) $\mathrm{MgSO}_{4}$ without $\mathrm{Pd} / \mathrm{Al}_{2} \mathrm{O}_{3}$; (b) $\mathrm{MgSO}_{4}$ with $\mathrm{Pd} / \mathrm{Al}_{2} \mathrm{O}_{3}$.
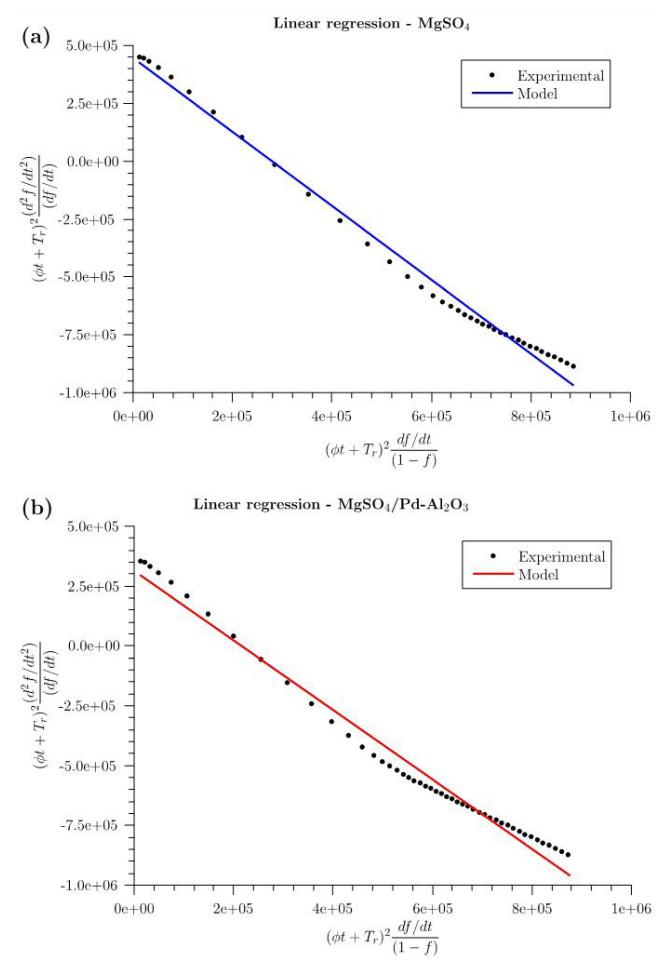

Figure 11. Linear regression plots: (a) $\mathrm{MgSO}_{4}$ without $\mathrm{Pd} / \mathrm{Al}_{2} \mathrm{O}_{3}$; (b) $\mathrm{MgSO}_{4}$ with $\mathrm{Pd} / \mathrm{Al}_{2} \mathrm{O}_{3}$. 
Table 1. Kinetic parameters associated with the $\mathrm{MgSO}_{4}$ decomposition processes with or without $20 \%$ (wt./wt.) of $\mathrm{Pd} / \mathrm{Al}_{2} \mathrm{O}_{3}$ material.

\begin{tabular}{lccc}
\hline Chemical Process & $\begin{array}{c}E_{a} \\
\left(\mathrm{~kJ} . \mathrm{mol}^{-1}\right)\end{array}$ & $n$ & $\mathrm{R}^{2}$ \\
\hline Without $\mathrm{Pd} / \mathrm{Al}_{2} \mathrm{O}_{3}$ & 368.2 & 1.6 & 0.991 \\
\hline With $\mathrm{Pd} / \mathrm{Al}_{2} \mathrm{O}_{3}$ & 258.8 & 1.4 & 0.981 \\
\hline
\end{tabular}

for the thermal decomposition reaction is about $100 \mathrm{~kJ} \cdot \mathrm{mol}^{-1}$ (nearly $30 \%$ ) when the catalyst is present, showing that $\mathrm{Pd} /$ $\mathrm{Al}_{2} \mathrm{O}_{3}$ can be a good alternative for attaining the purpose of the work.

\section{Conclusion}

On what touches the materials characterization, The XRD pattern of the synthesized $\mathrm{Pd} / \mathrm{Al}_{2} \mathrm{O}_{3}$ catalyst showed peaks with an extended base that is indicative of nanostructured particles. The comparison of the position of the peaks with the JCPDS files reveals a cubic phase of the $\gamma$-alumina. Rietveld refinement analyses showed that the synthesized catalyst has a composition of 95.24 wt. $\% \mathrm{Al}_{2} \mathrm{O}_{3}$ and 4.76 wt.\% $\mathrm{Pd}$ and crystallite size for palladium and alumina of $3.31 \mathrm{~nm}$ and 4.54 $\mathrm{nm}$, respectively. The FEG-SEM images of the synthesized catalyst using secondary electrons showed an orange-peel type of surface aspect with some small rods distributed over the surface. The backscattered electrons image highlights these small rods in bright tones, indicative of the palladium presence on the particle surface. The MgSO4 thermal decomposition with $\mathrm{Pd} / \mathrm{Al}_{2} \mathrm{O}_{3}$ catalyst showed that its product, as predicted by thermodynamics and mass balance, has a major presence of $\mathrm{MgO}$, and $\mathrm{Al}_{2} \mathrm{O}_{3}$ as well as small amounts of $\mathrm{Pd}$ and an oxidized phase containing $\mathrm{Mg}$ and $\mathrm{Al}$. The FEG-SEM secondary electrons image of the thermal decomposition product showed the existence of particles with small particle size, probably the catalyst, and a fractured surface, with the expected characteristics of the formed oxide.

Regarding the TGA and the kinetic modeling, it was observed that, in the presence of the catalyst, the $\mathrm{MgSO}_{4}$ decomposition begins at about $830{ }^{\circ} \mathrm{C}$, with $\mathrm{MgO}$ being the major magnesium bearing species. The presence of the $\mathrm{Pd} / \mathrm{Al}_{2} \mathrm{O}_{3}$ catalyst reduced the initial temperature of the sulfate thermal decomposition at approximately $120{ }^{\circ} \mathrm{C}$. The final temperature, in which the mass variation associated with the decomposition stops, was lowered to almost $100{ }^{\circ} \mathrm{C}$. In the kinetics studies, the sigmoid function was successfully used as approximation values of the weight fraction to minimize the error from the derivatives calculations. The $\mathrm{Pd} / \mathrm{Al}_{2} \mathrm{O}_{3}$ catalyst is a good alternative in reducing the thermal decomposition temperature of sulfates and was responsible for diminishing the process activation energy from $368.2 \mathrm{~kJ} \mathrm{~mol}^{-1}$ to 258.8 $\mathrm{kJ} . \mathrm{mol}^{-1}$. These results could be an interesting contribution to solar-based operations oriented to water-splitting cycles for hydrogen production, as it can provide some necessary conditions to lower heating efforts to start $\mathrm{SO}_{2}$ and $\mathrm{SO}_{3}$ production and increase the process energy efficiency.

\section{Acknowledgments}

The authors acknowledge their gratitude to Prof. Dr. Fátima Maria Zanon Zotin and the team in the Catalysis Research Group of the State University of Rio de Janeiro for their support in providing the first sample of the $\mathrm{Pd} / \mathrm{Al}_{2} \mathrm{O}_{3}$ material which inspired the use of this type catalyst in our project. It is also very important to be thankful to Instituto Tecnológico Vale (ITV) for the financial support in the project concerning the reductive decomposition of $\mathrm{MgSO}_{4}$. The institute contribution was essential for the consolidation of a research initiative for future developments in sulfates thermal decomposition. Moreover, this study was financed in part by the Coordenação de Aperfeiçoamento de Pessoal de Nível Superior - Brasil (CAPES) - Finance Code 001. The authors are also grateful to the Vice-Reitoria para Assuntos Acadêmicos (VRAc/PUC-Rio) and the Fundação Carlos Chagas Filho de Amparo à Pesquisa do Estado do Rio de Janeiro (FAPERJ) for the partnership and support throughout this research.

\section{References}

1. United Nations. Report of the Conference of the Parties on its twenty-first session. In: Conference of the Parties; 2016; Paris. Proceedings. Paris: United Nations; 2016. p. 42.

2. Sencar M, Pozeb V, Krope T. Development of EU (European Union) energy market agenda and security of supply. Energy. 2014;77:117-24.

3. Hanley ES, Deane J, Gallachóir BÓ. The role of hydrogen in low carbon energy futures-A review of existing perspectives. Renew Sustain Energy Rev. 2018;82:3027-45.

4. Abe JO, Popoola API, Ajenifuja E, Popoola OM. Hydrogen energy, economy and storage: review and recommendation. Int J Hydrogen Energy. 2019;44(29):15072-86.

5. Abbas HF, Wan Daud WMA. Hydrogen production by methane decomposition: a review. Int J Hydrogen Energy. 2010;35(3):116090.

6. Ashik UPM, Wan Daud WMA, Abbas HF. Production of greenhouse gas free hydrogen by thermocatalytic decomposition of methane-A review. Renew Sustain Energy Rev. 2015;44:22156.

7. Syed Muhammad AF, Awad A, Saidur R, Masiran N, Salam A, Abdullah B. Recent advances in cleaner hydrogen productions via thermo-catalytic decomposition of methane: admixture with hydrocarbon. Int J Hydrogen Energy. 2018;43(41):18713-34.

8. Norman J, Mysels K, Sharp R, Williamson D. Studies of the sulfur-iodine thermochemical water-splitting cycle. Int $\mathrm{J}$ Hydrogen Energy. 1982;7(7):545-56.

9. Onuki K, Kubo S, Terada A, Sakaba N, Hino R. Thermochemical water-splitting cycle using iodine and sulfur. Energy Environ Sci. 2009;2(5):491.

10. Barbarossa V, Brutti S, Diamanti M, Sau S, Demaria G. Catalytic thermal decomposition of sulphuric acid in sulphuriodine cycle for hydrogen production. Int J Hydrogen Energy. 2006;31(7):883-90.

11. Banerjee AM, Pai MR, Tewari R, Raje N, Tripathi AK, Bharadwaj SR, et al. A comprehensive study on Pt/Al 2 O 3 granular catalyst used for sulfuric acid decomposition step in sulfur-iodine thermochemical cycle: changes in catalyst structure, morphology and metal-support interaction. Appl Catal B. 2015;162:327-37.

12. Tizzoni AC, Corsaro N, D'Ottavi C, Licoccia S, Sau S, Tarquini P. Oxygen production by intermediate metal sulphates in sulphur based thermochemical water splitting cycles. Int J Hydrogen Energy. 2015;40(11):4065-83.

13. Bhosale RR, Kumar A, van den Broeke LJP, Gharbia S, Dardor $\mathrm{D}$, Jilani M, et al. Solar hydrogen production via thermochemical iron oxide-iron sulfate water splitting cycle. Int J Hydrogen Energy. 2015;40(4):1639-50. 
14. Bhosale R, Kumar A, AlMomani F, Gupta RB. Solar thermochemical $\mathrm{ZnO} / \mathrm{ZnSO} 4$ water splitting cycle for hydrogen production. Int J Hydrogen Energy. 2017;42(37):23474-83.

15. Soto-Díaz O, Orozco-Mena RE, Román-Aguirre M, RomeroParedes H, Camacho-Dávila AA, Ramos-Sánchez VH. Metal sulfate decomposition using green Pd-based catalysts supported on $\gamma \mathrm{Al} 2 \mathrm{O} 3$ and $\mathrm{SiC}$ : a common step in sulfur-family thermochemical cycles. Int J Hydrogen Energy. 2019;44(24):12309-14.

16. Habashi F. Handbook of extractive metallurgy. Handbook of extractive metallurgy. Vol. 2. Weinheim: Wiley-VCH Verlag GmbH \& Co. KGaA; 1997. 2435 p.

17. Vignes A. Extractive Metallurgy 1. Extractive Metallurgy 1. London: John Wiley \& Sons, Inc./ISTE Ltd; 2011. 344 p.

18. Atkins P, de Paula J. Physical chemistry thermodynamics, structure, and change. 10th ed. New York City: WH Freeman and Company New York; 2014. 1060 p.

19. Alpers C, Jambor JL, Nordstrom D. Sulfate minerals. In: Alpers CN, Jambor JL, Nordstrom D, editors. Sulfate minerals: crystallography, geochemistry, and environmental significance. Berlin: De Gruyter; 2001. 608 p.

20. King MJ, Davenport WG, Moats MS. Sulfuric acid manufacture: analysis, control, and optimization. In: King MJ, Davenport WG, Moats M, editors. Sulfuric acid manufacture. 2nd ed. Oxford: Elsevier; 2013. 608 p.

21. Redko A, Redko O, DiPippo R. Low-temperature energy systems with applicationsof renewable energy. Oxford: Elsevier; 2020. $394 \mathrm{p}$.

22. Souza R, Navarro R, Grillo AV, Brocchi E. Potassium alum thermal decomposition study under non-reductive and reductive conditions. J Mater Res Technol. 2019;8(1):745-51.

23. Bhosale RR. Solar hydrogen production via thermochemical magnesium oxide - Magnesium sulfate water splitting cycle. Fuel. 2020;275:117892.

24. Chou I-M, Seal RR, Wang A. The stability of sulfate and hydrated sulfate minerals near ambient conditions and their significance in environmental and planetary sciences. J Asian Earth Sci. 2013;62:734-58.

25. Peterson RC. Cranswickite $\mathrm{MgSO} 4.4 \mathrm{H} 2 \mathrm{O}$, a new mineral from calingasta, Argentina. Am Mineral. 2011;96(5-6):869-77.

26. Scheidema MN, Taskinen P. Decomposition thermodynamics of magnesium sulfate. Ind Eng Chem Res. 2011;50(16):9550-6.

27. Cross HE, Krieger W, Anschutz E, Reh L, Hirsch M, inventors; Metallgesellschaft AG, assignee. Process of producing magnesia with sulfuric acid recycle. Frankfurt, Germany patent US4096235A. 1978.

28. Kobayashi S, inventor. Process for reductive calcining of magnesium sulfate. Tokyo, Japan patent US4225573A. 1980.

29. Zambrano AR, inventor; Hanna Mining Co OP, assignee. Production of high purity and high surface area magnesium oxide. United States patent US 11722480 A 19800131; 4298379. 1981.

30. Lailach G, Gerken R, inventors. Process for the preparation of sulphur dioxide. Leverkusen, Germany patent US 4824655A. 1989.

31. Roche EG, Prasad J, inventors. Magnesium oxide recovery. Perth, Australia patent WO 2007/070973 A1. 2007.

32. Okhrimenko L, Favergeon L, Johannes K, Kuznik F. New kinetic model of the dehydration reaction of magnesium sulfate hexahydrate: application for heat storage. Thermochim Acta. 2020;687:178569.

33. Hulbert SF. Effect of processing parameters on the kinetics of decomposition of magnesium sulphate. Mater Sci Eng. 1968;2(5):262-8.
34. Lau KH, Cubicciotti D, Hildenbrand DL. Effusion studies of the thermal decomposition of magnesium and calcium sulfates. J Chem Phys. 1977;66(10):4532-9.

35. Schoubye PCS, Hansen OE, inventors; Haldor Topsoe AS, Niro Atomizer AS, assignee. A process for the regeneration of mixtures containing sulphuric acid and metal sulphates into sulphuric acid and metal oxides. Lyngby, Denmark patent EP 0125142 A2. 1984.

36. Plewa J, Steindor J. Kinetics of reduction of magnesium sulfate by carbon oxide. J Therm Anal. 1987;32(6):1809-20.

37. Souza B, Souza R, Santos I, Brocchi E. MgSO4 carbothermic reductive decomposition to produce a highly reactive $\mathrm{MgO}$ powder. J Mater Res Technol. 2020;9(2):1847-55.

38. Knittel DR, Lau KH, Hildenbrand DL. Effusion studies of the catalyzed decomposition of magnesium sulfate. J Phys Chem 1980;84(15):1890-4.

39. Papazian HA, Pizzolato PJ, Orrell RR. The thermal decomposition of aluminum sulfate and hafnium sulfate. Thermochim Acta. 1972;4(2):97-103.

40. Pysiak J, Glinka A. Thermal decomposition of basic aluminium potassium sulphate. Part I. Stages of decomposition. Thermochim Acta. 1981;44(1):21-8.

41. Pysiak J, Glinka A. Thermal decomposition of basic aluminium potassium sulfate. Part II. Kinetics of the reaction. Thermochim Acta. 1981;44(1):29-36.

42. Apte NG, Kiran E, Hassler JC, Chernosky JV. Kinetic modeling of thermal decomposition of aluminum sulfate. Chem Eng Commun. 1988;74(1):47-61.

43. Brownell WE. Reactions between alkaline-earth sulfates and cirstobalite. J Am Ceram Soc. 1963;46(3):125-8.

44. L'vov BV, Ugolkov VL. Kinetics of free-surface decomposition of magnesium and barium sulfates analyzed thermogravimetrically by the third-law method. Thermochim Acta. 2004;411(1):73-9.

45. Roine A. HSC chemistry [software]. Pori, Finland: Outotec; 2018.

46. Mello NM. Estudo cinético da reação de redução do NO pelo CO em catalisador de paládio suportado em alumina [dissertação]. Rio de Janeiro: Universidade do Estado do Rio de Janeiro; 2017.

47. Montani SS. Estudo da reação de redução do NO pelo CO em catalisadores modelo de paládio e cobre suportados em alumina e céria-zircônia [dissertação]. Rio de Janeiro: Universidade do Estado do Rio de Janeiro; 2014.

48. Cheary RW, Coelho A. A fundamental parameters approach to X-ray line-profile fitting. J Appl Cryst. 1992;25(2):109-21.

49. Coelho AA. TOPAS-Academic [software]. Brisbaine, Australia: TOPAS-Academic; 2007.

50. Vachuška J, Vobořil M. Kinetic data computation from nonisothermal thermogravimetric curves of non-uniform heating rate. Thermochim Acta. 1971;2(5):379-92.

51. Speyer R. Thermal analysis of materials. New York City: Marcel Dekker, Inc.; 1995. 298 p.

52. The Mathworks Inc. MATLAB (R2019b) [software]. Natick, MA: The Mathworks Inc; 2019.

53. Li A, Wang Y, Ren J, Zhang J, Li W, Guo C. Enhanced catalytic activity and stability over P-modified alumina supported Pd for anthraquinone hydrogenation. Appl Catal A Gen. 2020;593:117422.

54. Brocchi E, Cardoso J, Souza R, Santos I. Decomposição redutora do $\mathrm{MgSO} 4$ na presença de $\mathrm{H} 2(\mathrm{~g})$. In: XIV Jornadas Argentinas de Tratamiento de Minerales; 2018; Catamarca. Anais. Catamarca: UNCA; 2018. p. 451-60.

55. Cardoso JH. Decomposição redutora de $\mathrm{MgSO} 4.7 \mathrm{H} 2 \mathrm{O}$ na presença de $\mathrm{H} 2(\mathrm{~g})$ [dissertação]. Rio de Janeiro: Pontifícia Universidade Católica do Rio de Janeiro; 2018. 